\title{
Photo-alignment Properties of Main-Chain Liquid-Crystalline Polyimides Containing Chalcone Derivative
}

\author{
Takashi MiHARA, Yousuke NAKAO, and Naoyuki KOIDE ${ }^{\dagger}$ \\ Department of Chemistry, Faculty of Science, Science University of Tokyo, \\ 1-3 Kagurazaka, Shinjuku-ku, Tokyo 162-8601, Japan
}

(Received August 25, 2004; Accepted November 1, 2004; Published March 15, 2005)

\begin{abstract}
We investigated photo-alignment properties of main-chain polyimides prepared from acid anhydrides [4,4'-(hexafluoro-isopropylidene) diphthalic anhydride (6FDA) or 4,4'-biphthalic anhydride (BPDA)] and diamine derivatives containing a chalcone group. The polyimides in the film state were irradiated with linearly polarized UV (LPUV) light under different conditions. The liquid-crystalline (LC) cell was fabricated from the polyimide film irradiated with LPUV light. A mixture of a low molecular liquid crystal (4-cyano-4'-n-pentylbiphenyl: 5CB) and a dichroic dye was filled in the LC cell. 5CB in the LC cell was easily aligned perpendicular to the electric vector of the incident LPUV light. [DOI 10.1295/polymj.37.162]

KEY WORDS Chalcone / Liquid-Crystalline Polymer / Photo-alignment / Polyimide /
\end{abstract}

Alignment of liquid-crystalline (LC) molecules is important for liquid-crystalline displays (LCDs). Rubbing has been mainly employed for the uniaxial orientation of the LC molecules. However, rubbing has many disadvantages for LCDs such as generation of electrostatic charge and dust. Therefore, many methods of alignment technique for LC molecules focus on rubbing free methods. Photo-alignment procedure is a rubbing free method and is investigated as one of candidates that overcome the generation of electrostatic charge and dust for the rubbing process. ${ }^{1,2}$

The photo-alignment procedure is based on photochemical reactions such as photo-isomerization, photo-dimerization (photo-crosslinking) and photodecomposition. ${ }^{3-5}$ Photo-dimerization of photosensitive groups in polymers is employed to obtain a stable alignment of LC molecules. ${ }^{2,6-12}$ It is desirable that photo-dimerization occurs by the exposure of relatively longer wavelength of the UV light to avoid partial degradation of polymers by the irradiation. ${ }^{13}$ Photoreaction of chalcone moieties takes place by the irradiation with relatively longer wavelength of the UV light. Non-mesogenic photosensitive polymers containing chalcone derivatives have been studied for the photo-alignment film. ${ }^{13-19}$

The alignment of LC molecules is easily improved by the surface of LC polymers that exhibit a mesophase. This idea arises from the simple role of solubility for organic compounds, that is, like dissolves like. We already investigated thermal and photo-alignment properties of side-chain LC methacrylate polymers and side-chain polyimides bearing the chalcone derivative in the side chain. ${ }^{20-22}$

Generally, main-chain polyimides demonstrate good thermal and mechanical properties based upon the rigid rod-like chemical structure of the polymer backbone. Therefore, main-chain polyimides would be suitable candidates for the polymeric materials applied to the photo-alignment film, because many polyimide derivatives have been used as an alignment film of LCDs owing to excellent thermal and mechanical properties.

In this study, we investigate the extent of photoreaction of the chalcone-based main-chain polyimides prepared from two anhydride compounds $\left[4,4^{\prime}\right.$-(hexafluoro-isopropylidene) diphthalic anhydride (6FDA) or 4,4'-biphthalic anhydride (BPDA)] and diamine compounds with a chalcone derivative. The extent of photoreaction for the chalcone group in the polyimides was examined by UV-vis spectroscopy and/ or FT-IR measurements. The LC cell was fabricated from the polyimide film irradiated with the linearly polarized UV (LPUV) light. A mixture of 4-cyano4 '-n-pentylbiphenyl (5CB) and a dichroic dye was filled in the LC cell. The alignment direction of the LC molecules is discussed by dichroic ratio of the dichroic dye in the LC cell.

\section{EXPERIMENTAL}

\section{Materials}

We synthesized main-chain polyimides containing photosensitive chalcone moieties as shown in Figure 1. The polyimides were prepared from acid anhydrides $\left[4,4^{\prime}\right.$-(hexafluoro-isopropylidene) diphthalic anhydride (6FDA) or 4,4'-biphthalic anhydride (BPDA)] and diamine compounds containing a chalcone derivative. ${ }^{23}$ The polyimides with the 6FDA derivative

${ }^{\dagger}$ To whom correspondence should be addressed (Tel: +81-3-5228-8248, Fax: +81-3-3235-2214, E-mail: nkoide@ch.kagu.sut.ac.jp). 

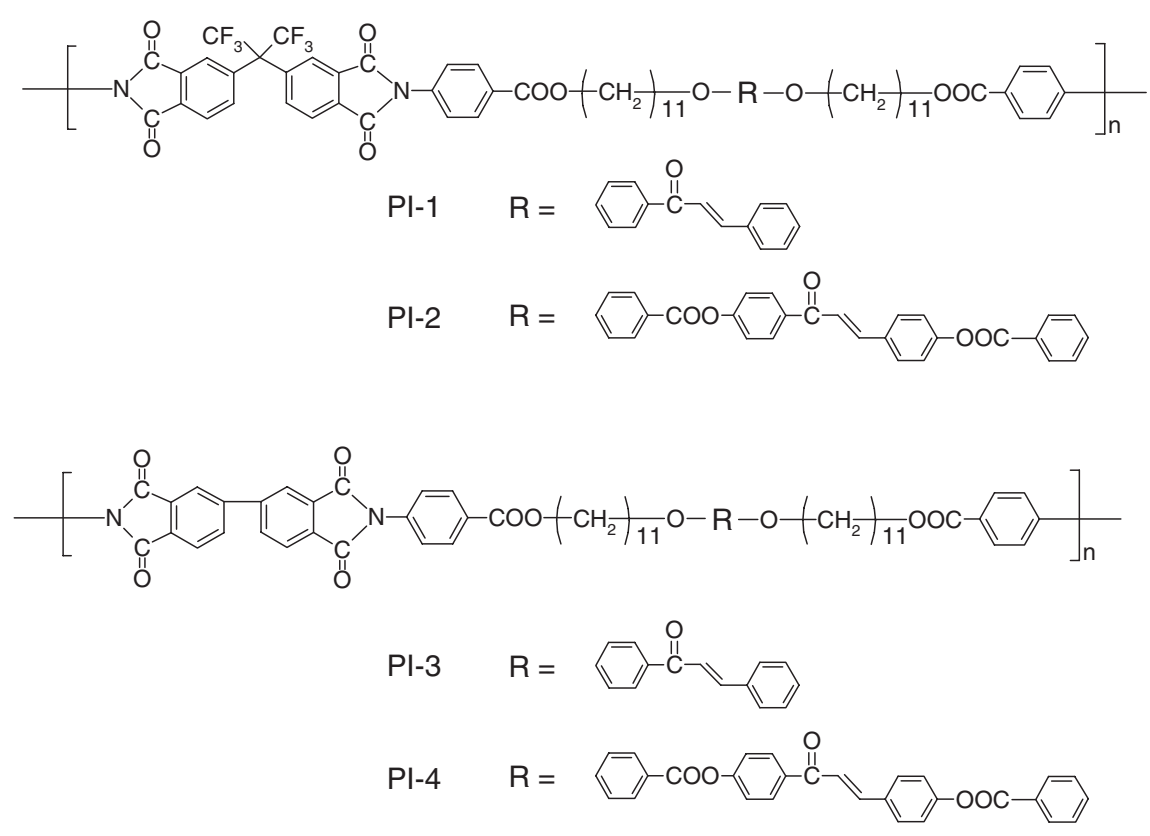

Figure 1. Chemical structures of main chain polyimides with a chalcone derivative.

Table I. Thermal properties and molecular weights of polyimides and polyamic acids

\begin{tabular}{|c|c|c|c|c|}
\hline Polymers & Thermal behavior $/{ }^{\circ} \mathrm{C}$ & $T_{\mathrm{d}} /{ }^{\circ} \mathrm{C}^{\mathrm{a}}$ & $\bar{M}_{\mathrm{n}}$ & $\bar{M}_{\mathrm{w}} / \bar{M}_{\mathrm{n}}$ \\
\hline PI-1 & $T_{\mathrm{g}} ; 110$ & 340 & 42,300 & 1.65 \\
\hline PI-2 & $T_{\mathrm{g}} ; 107$ & 380 & 20,600 & 1.79 \\
\hline PI-3 & 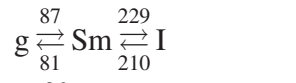 & 340 & 一 & 一 \\
\hline PI-4 & $\mathrm{g} \stackrel{96}{\rightarrow} \mathrm{Sm} \rightarrow$ Decomp. & 310 & - & - \\
\hline PAA-3 & $T_{\mathrm{g}} ; 89$ & 280 & 14,800 & 1.54 \\
\hline PAA-4 & $T_{\mathrm{g}} ; 105$ & $-^{\mathrm{b}}$ & 10,800 & 1.83 \\
\hline
\end{tabular}

(PI-1 and PI-2) were synthesized by a chemical imidization reaction. PI-1 and PI-2 were soluble in organic solvents such as tetrahydrofuran, chloroform and $N, N$ dimethylformamide. On the other hand, the polyimides with the BPDA derivative (PI-3 and PI-4) were obtained by a thermal curing reaction of the relative polyamic acids (PAA-3 and PAA-4). PAA-3 and PAA-4 were soluble in organic solvents such as tetrahydrofuran, chloroform and $N, N$-dimethylformamide, however PI-3 and PI-4 were insoluble in common organic solvents. Molecular weights and thermal properties of the polyimides and polyamic acids are summarized in Table I. Details of the synthesis of the polyimides are described in the literature. ${ }^{23}$

\section{Characterization}

UV-vis spectroscopy measurements were carried out with a HITACHI U-3410 spectrophotometer.
FT-IR measurements were carried out using a JEOL JIR-7000 with an infrared microscope unit.

\section{Linearly Polarized UV Irradiation}

PI-1 and PI-2 films were made by spin-coating on quartz or glass substrates from a chloroform solution (1 wt \%). PI-3 and PI-4 films were made by thermal curing $\left(1 \mathrm{mmHg}, 200^{\circ} \mathrm{C}\right)$ of the polyamic acid film prepared by spin-coating on quartz or glass substrates from a tetrahydrofuran solution ( $1 \mathrm{wt} \%)$ because PI-3 and PI-4 could not dissolve in organic solvent. The thickness of the polyimide films was several hundred angstroms. The polyimide film was irradiated with LPUV light under conditions as follows: (1) irradiation at room temperature, (2) irradiation above glass transition temperature (in the LC state of PI-3 and PI-4), (3) irradiation in the isotropic state of PI-3. The LPUV light intensity was $1.90 \mathrm{~mW} / \mathrm{cm}^{2}$ at $365 \mathrm{~nm}$ using a $500 \mathrm{~W}$ super high-pressure mercury lamp with a glan laser prism and a cut filter $(350 \mathrm{~nm})$.

\section{Alignment Properties of LC Molecules}

A sandwich type LC cell was fabricated in a parallel fashion of the polymer films irradiated with the LPUV light. A mixture of the low molecular weight liquid crystal (4-cyano-4'-n-pentylbiphenyl: $5 \mathrm{CB}$ ) and dichroic dye (M137) was injected in the LC cell. The thickness of the LC cell was $10 \mu \mathrm{m}$. The alignment of the LC molecules was investigated based on the dichroic ratio (DR) of the absorbance at $640 \mathrm{~nm}$ for the dichroic dye, obtained by polarized UV-vis spectroscopy measurements. DR is defined as follow: ${ }^{14}$

Dichroic ratio $(\mathrm{DR})=\left(A_{\text {para }}-A_{\text {per }}\right) /\left(A_{\text {para }}+A_{\text {per }}\right)$ 
$A_{\text {para }}$ and $A_{\text {per }}$ indicate absorbance parallel and perpendicular to the electric vector of the incident LPUV light, respectively.

\section{RESULTS AND DISCUSSION}

\section{Photoreaction of Chalcone Derivatives in Polyimides}

Figure 2a displays the UV-vis spectra of the PI-1 film irradiated with LPUV light at $25^{\circ} \mathrm{C}$ with different irradiation times. The absorption peak around $345 \mathrm{~nm}$ decreased with irradiation time, while the absorption peak around $260 \mathrm{~nm}$ slightly increased. A similar tendency concerning the absorption peaks was observed for the PI-3 film irradiated with the LPUV light. Figure $2 b$ shows the UV-vis spectra of the PI-4 film irradiated at $160{ }^{\circ} \mathrm{C}$ with different irradiation
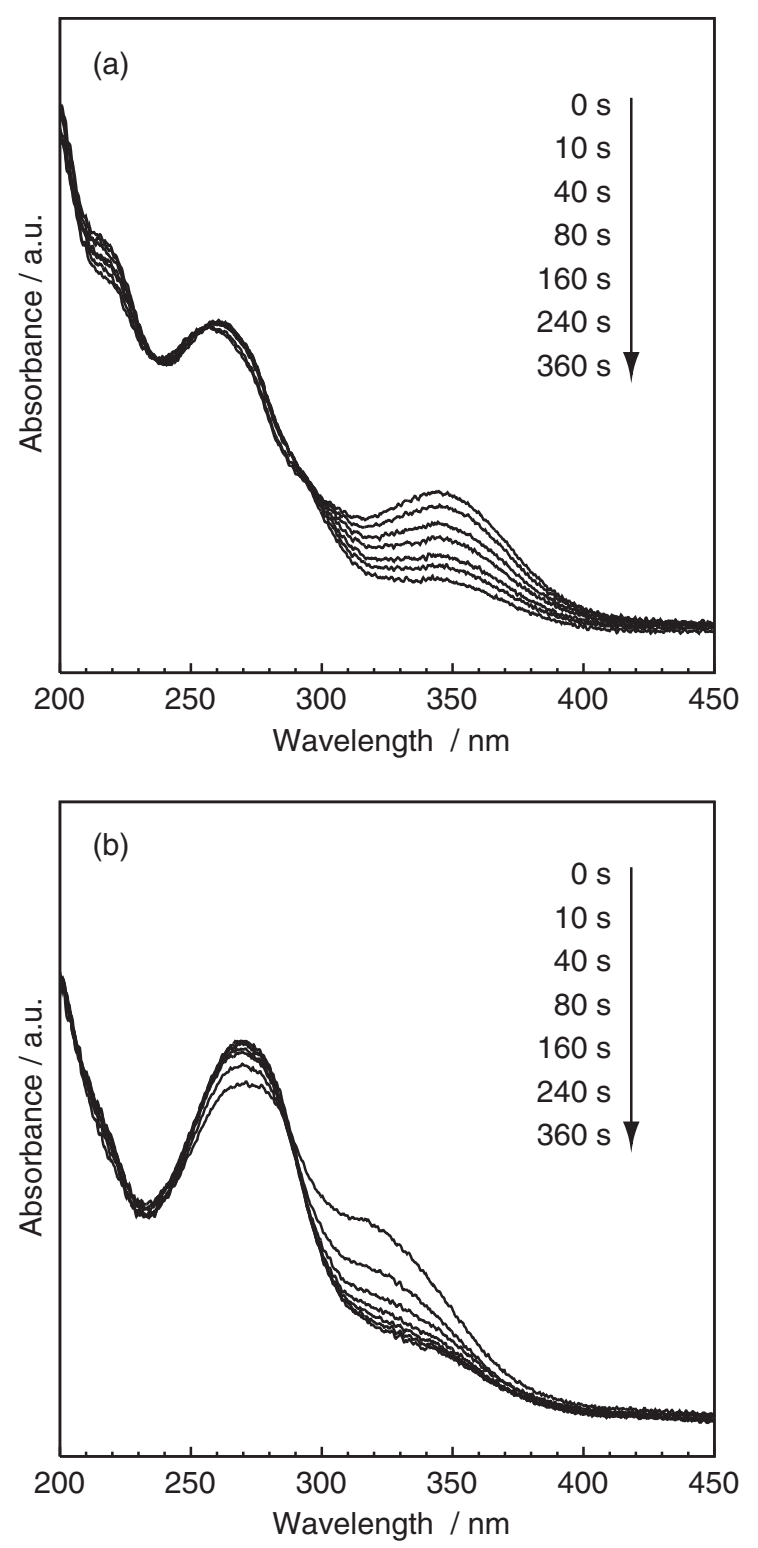

Figure 2. UV-vis spectra of PI-1 (a) and PI-4 (b) in film irradiated with LPUV light. Irradiation temperatures of PI-1 (a) and PI-4 (b) are $25^{\circ} \mathrm{C}$ and $160^{\circ} \mathrm{C}$, respectively. times. The absorption peak around $320 \mathrm{~nm}$ decreased with irradiation time. In contrast, the peak around $270 \mathrm{~nm}$ increased with irradiation time. The same concerning the changes in the UV-vis spectra was observed for the irradiated PI-2 film. The wavelength of the peak in the longer wavelength region was dependent upon the chemical structure of the chalcone derivative. The peak around $345 \mathrm{~nm}$ or around 320 $\mathrm{nm}$ as shown in Figure $2 \mathrm{a}$ or in Figure $2 \mathrm{~b}$ was assigned to the trans chalcone derivative. The peak near 260-270 nm consisted of the absorption peak of the anhydride derivative (6FDA or BPDA) and absorption peak of the cis isomer or dimer of the chalcone derivative. ${ }^{14,24,25}$ The absorption peak around $345 \mathrm{~nm}$ or around $320 \mathrm{~nm}$ greatly diminished by LPUV irradiation for 10-40 s. However, remarkable decrease in the peak around $345 \mathrm{~nm}$ or around $320 \mathrm{~nm}$ was not detected after the LPUV irradiation above 160-240 s.

Photo-isomerization and photo-dimerization are photoreactions of chalcone derivative. ${ }^{24,25}$ Makita et al. investigated the photo-dimerization of chalcone derivative in poly(4-fluoro-4'-methacryloyloxy chalcone) by FT-IR measurements. ${ }^{13,14}$ The photo-dimerization of chalcone derivative by UV irradiation is explained by the shift or broadening to the higher wavenumber of the peak attributed to the carbonyl group and decrease of the peak assigned to olefin $\mathrm{C}-\mathrm{H}$ out of plane bending in the chalcone derivative by FT-IR measurements.

We measured FT-IR spectra of the polymer films before and after LPUV irradiation for $360 \mathrm{~s}$ to investigate the photoreaction of chalcone derivative. Two typical changes of the peak in the FT-IR spectrum of the irradiated polyimide film were observed compared to FT-IR spectrum of the polyimide film before LPUV irradiation: decrease in the peak near $985 \mathrm{~cm}^{-1}$ assigned to olefin $\mathrm{C}-\mathrm{H}$ out of plane bending for the trans chalcone groups and shift or broadening to the higher wavenumber of the peak near $1660 \mathrm{~cm}^{-1}$ attributed to the ketone group in the FT-IR spectra of the irradiated polymer film. The decrease in the peak near $985 \mathrm{~cm}^{-1}$ and shift or broadening of the peak near $1660 \mathrm{~cm}^{-1}$ would indicate the disappearance of the double bond in the chalcone derivative. . $^{13,14,26-28}$ The shift and broadening of the peak near 1660 $\mathrm{cm}^{-1}$ would originate from the decrease in conjugation of the double bond and the carbonyl group due to cycloaddition (photo-dimerization) reaction of the double bond in the chalcone derivative. In the FT-IR spectra of the irradiated polymer films, other peaks except above two peaks based upon the photoreaction of the chalcone derivative did not change remarkably. These results support the photo-dimerization of the chalcone derivative and no photo-decomposition of the polymer backbone of the polyimides. 
Table II. Extent of photoreaction of chalcone derivatives in polyimides

\begin{tabular}{ccc}
\hline Polymers & $\begin{array}{l}\text { Irradiation } \\
\text { temperatures } /{ }^{\circ} \mathrm{C}\end{array}$ & $\begin{array}{l}\text { Extent of } \\
\text { photo-reaction } / \%^{\mathrm{a}}\end{array}$ \\
\hline PI-1 & 25 & 18 \\
& 160 & 10 \\
PI-2 & 25 & 33 \\
& 160 & 31 \\
PI-3 & 25 & 54 \\
& 160 & 57 \\
PI-4 & 250 & 90 \\
& 25 & 35 \\
& 160 & 77 \\
& 200 & 76 \\
\hline
\end{tabular}

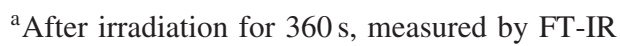

The extent of photoreaction of the chalcone derivative irradiated for $360 \mathrm{~s}$ was investigated by FT-IR. The extent of photoreaction of the chalcone derivative was calculated by decrease in absorbance of the peak near $985 \mathrm{~cm}^{-1}$ in the FT-IR spectra of the polymer film before and after LPUV irradiation. The extent of photoreaction after LPUV irradiation for $360 \mathrm{~s}$ is summarized in Table II. For PI-1 and PI-2 that display no mesophases, the extent of photoreaction of the chalcone derivative above glass transition temperature was smaller than that at $25^{\circ} \mathrm{C}$.

The extent of photoreaction at $25^{\circ} \mathrm{C}$ for PI- 1 was $18 \%$ as shown in Table II. However, the extent of photoreaction for PI-1 obtained from the change of the UV-vis spectra as shown in Figure 2a would be larger than calculated from FT-IR. The difference of the extent of photoreaction obtained from UV-vis and FT-IR was produced because photoreaction of the chalcone derivative detected by FT-IR measurements would be different from that by UV-vis measurements. Photo-isomerization and photo-dimerization of the chalcone derivative can be estimated by decrease in the peak near 320 or $345 \mathrm{~nm}$ in UV-vis spectroscopy measurements, while photo-dimerization can be detected by decrease in the peak near $985 \mathrm{~cm}^{-1}$ and the shift or broadening of the peak near $1660 \mathrm{~cm}^{-1}$ in FT-IR measurements. Therefore, the experimental results obtained by UV-vis and FT-IR spectroscopy measurements indicate that photo-isomerization as well as photo-dimerization of the chalcone derivative in PI-1 may occur by LPUV irradiation.

The extent of photoreaction of the chalcone derivative in PI-3 and PI-4 above glass transition temperature (in the smectic phase) was larger than that at room temperature $\left(25^{\circ} \mathrm{C}\right)$. The higher extent of photoreaction of the chalcone derivative in PI-3 and PI-4 above glass transition temperature may originate from the orientation of mesogenic groups in spite of the thermal motion of polymer backbones. However, the extent of photoreaction of the chalcone derivative of PI-3 in the isotropic state was largest. This indicates that the extent of photoreaction would be affected by not only the orientation of mesogenic groups but also thermal motion of polymer backbones due to higher irradiation temperature. The temperature dependence of the extent of photoreaction of the chalcone derivative in PI-3 and PI-4 was different from that in PI-1 and PI-2. The extent of photoreaction of the chalcone derivative would be influenced by many factors such as the chemical structure of the chalcone derivative, phase structure, and thermal motion of polymer backbones.

\section{Alignment of $5 C B$ in LC Cell Fabricated from Irradi- ated Polyimide Film}

Figure 3 shows an angular dependence for the absorption of the dichroic dye in the LC cell fabricated from the PI-4 film irradiated with the LPUV light in the LC state. Before UV irradiation, absorption of the dichroic dye was independent of the polarized angle in the polarized UV-vis spectroscopy measurements. After UV irradiation, anisotropy of absorption of the dichroic dye was detected. The absorption in the perpendicular direction to the electric vector of the incident LPUV light was larger than that in the parallel direction to the electric vector. This indicates that $5 \mathrm{CB}$ is aligned randomly before $\mathrm{UV}$ irradiation, and that $5 \mathrm{CB}$ is aligned perpendicular to the electric vector of the incident LPUV light after irradiation.

We calculated DR of the dichroic dye in the LC cell according to the equation shown in the experimental

0
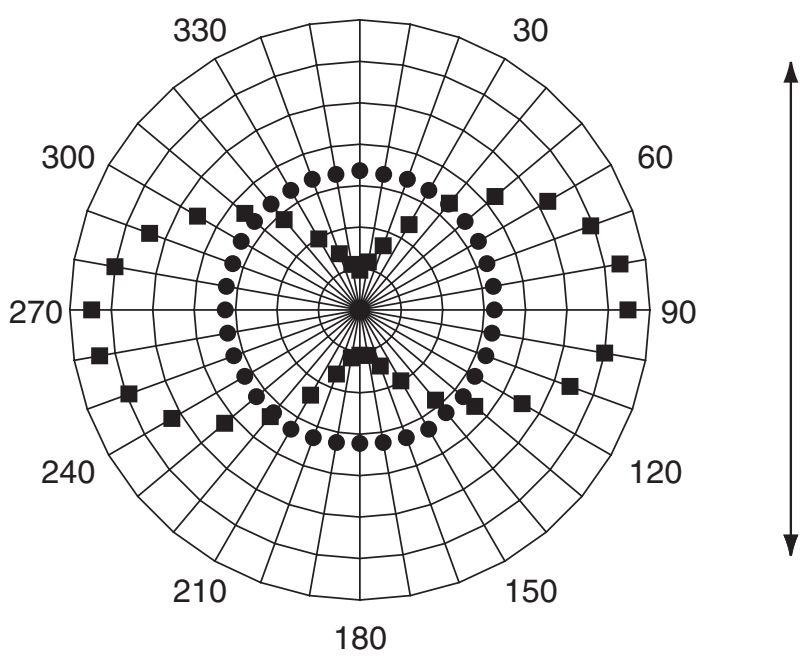

Figure 3. Angular dependence for absorption of dichroic dye in the LC cell fabricated from the PI-4 film irradiated with the LPUV light at $160^{\circ} \mathrm{C}$ for $0 \mathrm{~s}$ (filled circles) and $360 \mathrm{~s}$ (filled squares). Arrow indicates electric vector of the incident LPUV light. 


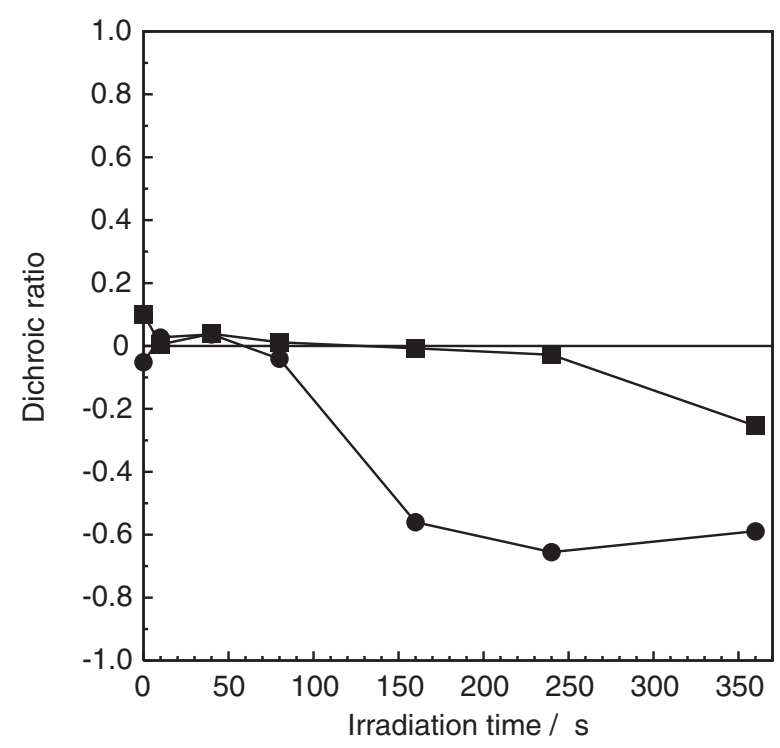

Figure 4. Dichroic ratios of the dichroic dye in the LC cell fabricated from the PI-1 film irradiated with LPUV light at $25^{\circ} \mathrm{C}$ (filled circles) and at $160^{\circ} \mathrm{C}$ (filled squares).

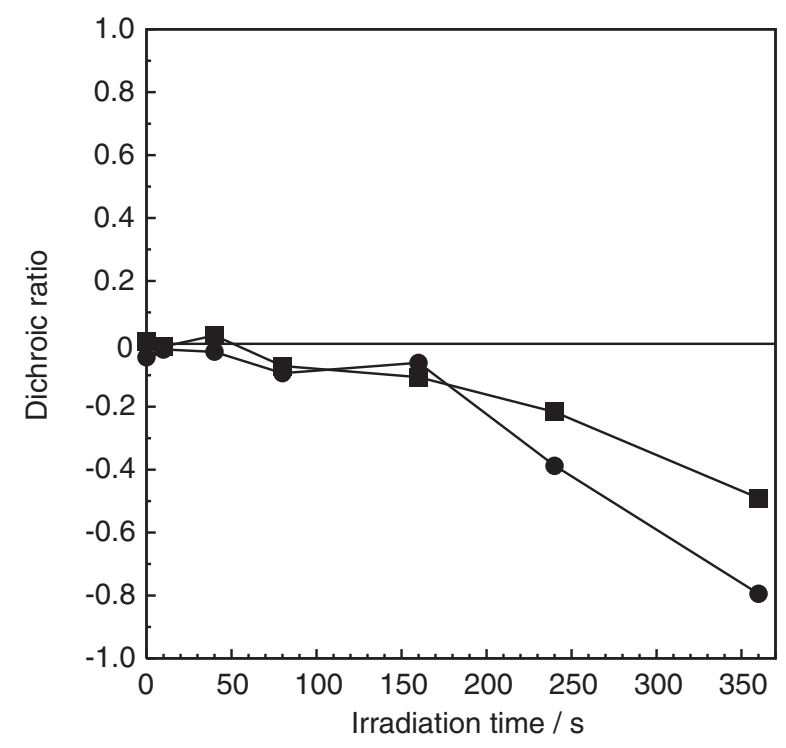

Figure 5. Dichroic ratios of the dichroic dye in the LC cell fabricated from the PI-2 film irradiated with LPUV light at $25^{\circ} \mathrm{C}$ (filled circles) and at $160^{\circ} \mathrm{C}$ (filled squares).

section and investigated the alignment of $5 \mathrm{CB}$ based on the DR. ${ }^{21}$ Positive DR indicates that 5CB is aligned parallel to the electric vector of the incident LPUV light, while negative DR shows that $5 \mathrm{CB}$ is aligned perpendicular to the electric vector of the LPUV light.

The relationship between LPUV irradiation time and DR of the LC cell using PI-1 and PI-2 is displayed in Figures 4 and 5, respectively. DR was around zero for the LC cell using the PI-1 film or the PI-2 film irradiated with LPUV light for $0-80 \mathrm{~s}$. 5CB in the cell was aligned perpendicular to the glass substrate coated with the polyimide film. Homeotropic alignment of

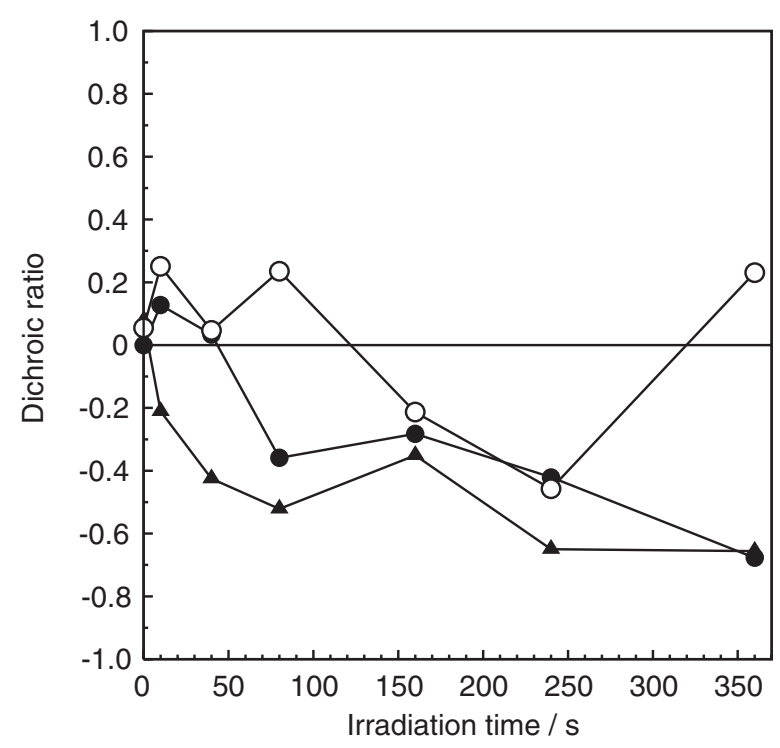

Figure 6. Dichroic ratios of the dichroic dye in the LC cell fabricated from the PI-3 film irradiated with LPUV light at $25^{\circ} \mathrm{C}$ (filled circles), at $160^{\circ} \mathrm{C}$ (filled triangles, LC state) and at $250^{\circ} \mathrm{C}$ (open circles, isotropic state).

5CB was confirmed by conoscopic observation of polarized optical microscopy measurements. In the case of the LC cell using the PI-1 film or PI-2 film irradiated with LPUV light over $240 \mathrm{~s}$ at room temperature, absolute DR was larger than that at $160^{\circ} \mathrm{C}$. This demonstrates that the LPUV irradiation at $160^{\circ} \mathrm{C}$ does not result in uniaxial alignment of $5 \mathrm{CB}$ in the LC cell. $5 \mathrm{CB}$ in the LC cell using the PI-1 film or PI-2 film irradiated for 360 seconds at room temperature was aligned perpendicular to the electric vector of the LPUV light.

The relationship between LPUV irradiation time and DR of the LC cell using PI-3 is shown in Figure 6. In the case of the LC cell using the PI-3 film irradiated with LPUV light at room temperature over $80 \mathrm{~s}$ or in the LC state over $10 \mathrm{~s}$, the sign of DR was negative. This shows that the $5 \mathrm{CB}$ is aligned perpendicular to the electric vector of the LPUV light. In contrast, for the LC cell using the PI-3 film irradiated in the isotropic state, the sign of DR changes with increasing irradiation time. The alignment of 5CB in the LC cell using the PI-3 film irradiated in the isotropic state was dependent upon LPUV irradiation time.

In the LC state of PI-3, the main chain of the polyimide moves thermally. However, absolute DR for the LC cell using the PI-3 film irradiated in the LC state was relatively larger than that for the LC cell using the PI-1 film irradiated above glass transition temperature. This shows that the LC state of PI-3 is important for the relatively large absolute DR. Large absolute DR for the LC cell using the PI-3 film would originate from the relatively larger extent of photoreaction of the PI-3 film irradiated in the LC state as 


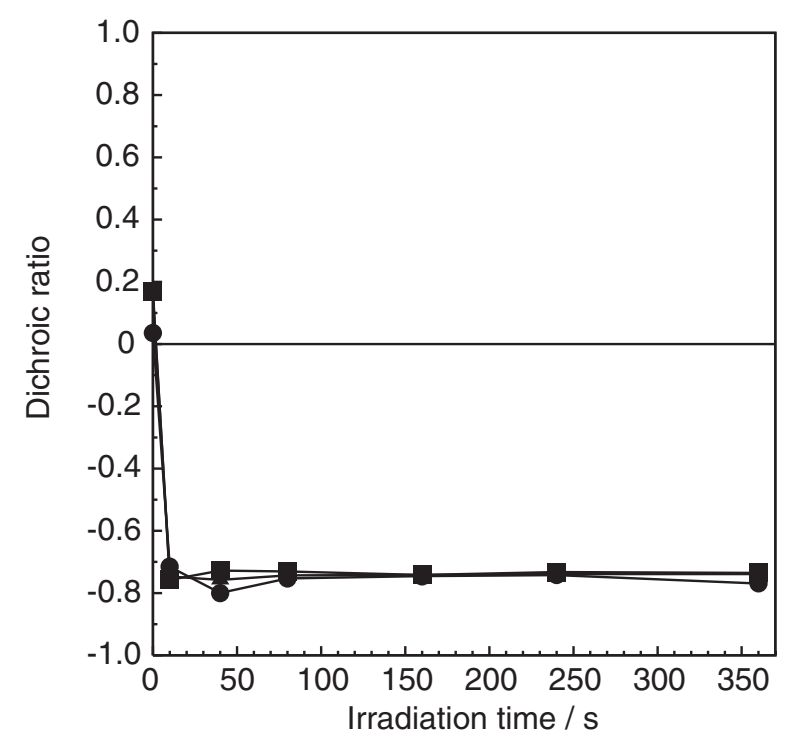

Figure 7. Dichroic ratios of the dichroic dye in the LC cell fabricated from the PI-4 film irradiated with LPUV light at $25^{\circ} \mathrm{C}$ (filled circles), at $160^{\circ} \mathrm{C}$ (filled squares, LC state) and at $200^{\circ} \mathrm{C}$ (filled triangles, LC state).

shown in Table II. In PI-3 in the isotropic state, the main chain moves thermally. The magnitude of the thermal motion of the main chain in the isotropic state would be larger than that in the LC state. Therefore, the thermal motion of the main chain of PI-3 in the isotropic state would interfere with the generation of anisotropy in the PI-3 film. The photoreaction of the chalcone derivatives in PI-3 occurs isotropically in spite of LPUV irradiation. Thus, no uniaxial alignment of 5CB was observed for the LC cell using the PI-3 film irradiated in the isotropic state.

Figure 7 shows the relationship between LPUV irradiation time and DR of the LC cell using the PI4 film. The sign of DR was negative regardless of irradiation time or irradiation temperature. $5 \mathrm{CB}$ in the LC cell using the irradiated PI-4 film was aligned perpendicular to the electric vector of the LPUV light. Absolute DR was also relatively large compared to that for the LC cell using other polyimides. The remarkable uniaxial alignment of 5CB was achieved using irradiated PI-4 film.

DR of the LC cell using the PI-3 film or the PI-4 film irradiated at room temperature for $360 \mathrm{~s}$ was similar to that at $160^{\circ} \mathrm{C}$. DR of the LC cell using the PI-4 film irradiated at room temperature was almost the same as that in the LC state, regardless of irradiation time. PI-3 and PI-4 films were prepared by thermal curing reaction of each polyamic acid at $200^{\circ} \mathrm{C}$. Therefore, two processes in imidization of polyamic acids and annealing in the LC state of the resulting polyimides would occur at the thermal curing temperature $\left(200^{\circ} \mathrm{C}\right)$.

We examined the anisotropy in the polyimide film by polarized UV-vis spectroscopy measurements to clarify the alignment mechanism of 5CB. Although we observed anisotropic absorption of the peaks near 270,320 or $345 \mathrm{~nm}$ in the UV-vis spectra of polyimide film, we cannot explain the relationship between anisotropy in the polyimide film based upon the anisotropic absorption of the peak and alignment of $5 \mathrm{CB}$ in the LC cell. Therefore, we can not clarify the mechanism of photo-alignment behavior for the irradiated polyimide films at present. Photo-alignment of polyimides is based upon photo-decomposition of the main chain of polyimides. ${ }^{29}$ Nishikawa et al. proposes that the selective photo-decomposition of polyimide causes anisotropic van der Waals force which aligns the liquid crystal along its optical axis in residual polyimide chain. ${ }^{30}$ Sakamoto et al. proposes that large anisotropy of the linearly polarized ultraviolet exposed poly(4,4'-oxydiphenylene-1,2,3,4-cyclobutanetetracarboximide) film is caused by anisotropic cleavage of the cyclobutane rings. ${ }^{31}$ However, we could not detect changes of the peaks in FT-IR spectra after LPUV irradiation based upon the photo-decomposition of main chains of the polyimide. Therefore, the photo-alignment mechanism of the chalconebased polyimides would be related to the photoreaction of the chalcone derivatives in polyimides.

We investigated thermal stability of the alignment properties of the polyimide film in the LC cell. We employed the LC cell fabricated from the polyimide films irradiated with the LPUV light for $360 \mathrm{~s}$ in the LC state or at room temperature because the LC cell shows the relatively large absolute DR. After each LC cell was left for $15 \mathrm{~min}$ at $200^{\circ} \mathrm{C}$, we examined $\mathrm{DR}$ at room temperature. DRs before and after annealing at $200^{\circ} \mathrm{C}$ are summarized in Table III. Absolute DR of the LC cell using the irradiated PI-1 film or irradiated PI-2 film decreased after annealing, although DR was still negative. In contrast, after annealing, absolute DR of the LC cell using the irradiat-

Table III. Dichroic ratios of dichroic dye in the LC cell before and after annealing

\begin{tabular}{|c|c|c|c|}
\hline \multirow{2}{*}{ Polymers } & \multirow{2}{*}{$\begin{array}{l}\text { Irradiation } \\
\text { temperature } /{ }^{\circ} \mathrm{C}\end{array}$} & \multicolumn{2}{|c|}{ Dichroic ratios $^{\mathrm{a}}$} \\
\hline & & Before annealing $^{\mathrm{b}}$ & After annealing \\
\hline PI-1 & 25 & -0.59 & -0.44 \\
\hline PI-2 & 25 & -0.79 & -0.46 \\
\hline \multirow[t]{2}{*}{ PI-3 } & 25 & -0.68 & -0.67 \\
\hline & 160 & -0.66 & -0.67 \\
\hline \multirow[t]{3}{*}{ PI-4 } & 25 & -0.77 & -0.75 \\
\hline & 160 & -0.74 & -0.72 \\
\hline & 200 & -0.74 & -0.74 \\
\hline
\end{tabular}

${ }^{a}$ The negative value indicates that $5 \mathrm{CB}$ is aligned perpendicular to the electric vector of the incident LPUV light. ${ }^{\mathrm{b}}$ After irradiation for $360 \mathrm{~s}$ 
ed PI-3 film or irradiated PI-4 film did not change. Uniaxial alignment of $5 \mathrm{CB}$ in the LC cell using the irradiated PI-3 film or irradiated PI-4 film was still maintained. Uniaxial alignment of 5CB was more stable than that in the LC cell using the irradiated PI-1 film or irradiated PI-2 film. The LC state that PI-3 and PI-4 exhibit at $200^{\circ} \mathrm{C}$, and rigid chemical structure of PI-3 and PI-4 would be important for the thermal stability of the uniaxial alignment of 5CB.

Non-mesomorphic photosensitive polymers containing chalcone derivatives in the side chain have been studied for the photo-alignment film. ${ }^{13-19,22,26,27,32}$ The alignment direction of 5CB in the LC cell using the irradiated poly(4-methacryloyloxy chalcone) (PM4Ch) film was perpendicular to the electric vector of the incident LPUV light. ${ }^{14} \mathrm{DR}$ for the LC cell using the irradiated PM4Ch film was about -0.5 . LC alignment capability for the LC cell using the irradiated PM4Ch film was preserved up to $170^{\circ} \mathrm{C}$. Here, the alignment direction of $5 \mathrm{CB}$ in the LC cell using irradiated PI-4 film was the same as that in the LC cell using the irradiated PM4Ch film. Although it would be difficult to compare the alignment capability of the irradiated PM4Ch film with that of the irradiated PI-4 film because of differences in the experimental conditions such as thickness of LC layer, etc., DR (about -0.7) for the LC cell using the irradiated PI-4 film may be superior to that for the LC cell using the irradiated PM4Ch film.

\section{REFERENCES}

1. K. Ichimura, Chem. Rev., 100, 1847 (2000).

2. M. O'Neill and S. M. Kelly, J. Phys. D: Appl. Phys., 33, R67 (2000).

3. K. Ichimura, Y. Hayashi, H. Akiyama, T. Ikeda, and N. Ishizuki, Appl. Phys. Lett., 63, 449 (1993).

4. T. Seki, K. Ichimura, R. Fukuda, T. Tanigaki, and T. Tamaki, Macromolecules, 29, 892 (1996).

5. K. Ichimura, H. Akiyama, K. Kudo, N. Ishizuki, and S. Yamamura, Liq. Cryst., 20, 423 (1996).

6. M. Schadt, K. Scmitt, V. Kozinkov, and V. Chigrinov, Jpn. J. Appl. Phys., 31, 2155 (1992).

7. Y. Iimura, T. Saitoh, S. Kobayashi, and T. Hashimoto, J. Photopolym. Sci. Technol., 2, 257 (1995).

8. X. Li, D. H. Pei, S. Kobayashi and Y. Iimura, Jpn. J. Appl. Phys., 36, L432 (1997).
9. K. Ichimura, Y. Akita, H. Akiyama, K. Kudo, and Y. Hayashi, Macromolecules, 30, 903 (1997).

10. G. P. Bryan-Brown and I. C. Sage, Liq. Cryst., 20, 825 (1996).

11. N. Kawatsuki, H. Takatsuka, T. Yamamoto, and H. Ono, Jpn. J. Appl. Phys., 36, 6464 (1997).

12. N. Kawatsuki, K. Takatani, T. Yamamoto, and H. Ono, Polym. J., 30, 946 (1998).

13. Y. Makita, T. Ogawa, S. Kimura, M. Nakata, S. Kimura, Y. Matsuki, and Y. Takeuchi, IDW '97, FMC3-3, 363 (1997).

14. Y. Makita, T. Natsui, S. Kimura, S. Nakata, M. Kimura, Y. Matsuki, and Y. Takeuchi, J. Photopolym. Sci. Technol., 11, 187 (1998).

15. Y. Makita, T. Natsui, S. Kimura, M. Nakata, S. Kimura, Y. Matsuki, and Y. Takeuchi, SID 98 Digest, LP-H, 750 (1998).

16. S. Nakata, K. Kuriyama, M. Kimura, T. Natsui, Y. Makita, Y. Matsuki, N. Bessho, and Y. Takeuchi, SID 99 Digest, LP-3, 512 (1999).

17. D.-S. Seo and J.-Y. Hwang, Jpn. J. Appl. Phys., 39, L816 (2000).

18. D.-S. Seo and J.-Y. Hwang, Jpn. J. Appl. Phys., 39, L1239 (2000).

19. M. Kimura, S. Nakata, Y. Makita, Y. Matsuki, A. Kumano, Y. Takeuchi, and H. Yokoyama, Jpn. J. Appl. Phys., 40, L352 (2001).

20. T. Mihara, M. Tsutsumi, and N. Koide, Mol. Cryst. Liq. Cryst., 382, 53 (2002).

21. T. Mihara, M. Tsutsumi, and N. Koide, Polym. J., 34, 347 (2002).

22. T. Mihara, M. Tsutsumi, and N. Koide, Mol. Cryst. Liq. Cryst., 412, 247 (2004).

23. T. Mihara, Y. Nakao, and N. Koide, Polym. J., 36, 899 (2004).

24. S. A. Zahir, J. Appl. Polym. Sci., 23, 1355 (1979).

25. S. P. Panda, J. Appl. Polym. Sci., 18, 2317 (1974).

26. D. M. Song, D. M. Shin, K. Y. Choi, and M. H. Yi, Colloids Surf. A, 198-200, 875 (2002).

27. K.-S. Choi, H.-W. Kim, Y.-B. Kim, and J.-D. Kim, Liq. Cryst., 31, 639 (2004).

28. R. Balaji and S. Nanjundan, React. Funct. Polym., 49, 77 (2001).

29. J. Lu, S. V. Deshpande, E. Gulari, J. Kanicki, and W. L. Warren, J. Appl. Phys., 80, 5028 (1996).

30. M. Nishikawa, B. Taheri, and J. L. West, Mol. Cryst. Liq. Cryst., 325, 63 (1998).

31. K. Sakamoto, K. Usami, T. Araya, and S. Ushioda, Jpn. J. Appl. Phys., 38, L1435 (1999).

32. J.-Y. Hwang, D.-S. Seo, J.-H. Son, and D. H. Suh, Jpn. J. Appl. Phys., 40, L761 (2001). 